DOI: $10.15503 /$ onis2014-225-231

\title{
SYNESTEZJA - WYZWANIE DLA KULTURY WZROKOCENTRYCZNEJ
}

Zuzanna Kozłowska, zuzannakozlowska.uam@gmail.com

Uniwersytet im. Adama Mickiewicza w Poznaniu

Ul. Wieniawskiego 1, 61-712 Poznań

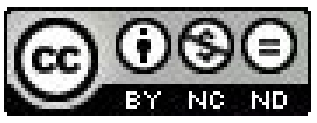

\section{STRESZCZENIE}

Współczesna kultura, pomimo podejmowanych w ubiegłym stuleciu prób obalenia bergsonowskiej „tyranii oka”, po raz kolejny popada w pułapkę „fetyszyzmu spojrzenia”. Niniejszy artykuł ma na celu opozycyjne usytuowanie synestezji wobec wzrokocentrycznej machiny kulturowej oraz wskazanie na rozmaite kinematograficzne, architektoniczne, sportowo-artystyczne, chronometryczne, a nawet edukacyjne i kulturowe doświadczenia synestetyczne wieku XXI, sprzeciwiające się okulocentrycznej wizji świata.

Słowa kluczowe: synestezja, wzrokocentryzm, antywzrokocentryzm, kultura wizualna, somatopoetyka, somatyczność, cielesność

Synaesthesia: challenging the vision-obsessed culture

\section{Abstract}

Once again contemporary culture, regardless of the XX $X^{\text {th }}$ century attempts to abolish Bergson's "tyranny of the eye", falls victim of the fetishism of the sight. The purpose of this paper is to portray synaesthesia as an antiocularcentric cultural device, as well as to indicate various cinematographic, architectural, sports, artistic, chronometric and even educational synaesthetic XXIIt century cultural experiences which defy the ocularcentric vision of the world.

Keywords: synaesthesia, ocularcentrism, antiocularcentrism, visual culture, somatic poetics, corporeality

W studium kultury wizualnej Downcast Eyes: The Denigration of Vision in Twentieth-Century French Thought Martin Jay przedstawił orientacyjną mape przemian kulturowych, określanych zbiorczo mianem dyskursu antywzrokocentrycznego. Wzrokocentryzm, który należałoby definiować jako manifestujące się na rozmaitych płaszczyznach kulturowych, takich jak dyskurs naukowy, literatura, filozofia czy sztuki plastyczne, znaczące „uprzywilejowanie [odwołujących się do zmysłu wzroku - przyp. autora] schematów poznawczych, metafor, sposobów ujmowania rzeczywistości i kreowania artefaktów ${ }^{\prime \prime 1}$, determinowat, według M. Jaya, zachodnią kulturę aż do schyłku XIX w. Francuski filozof Henri Bergson, jeden z czołowych myślicieli antyokulocentrycznych przełomu wieków, nazwał ten stan „tyranią oka”2. Zmierzch XIX w. wyznacza początek spektakularnej „antywizualnej rebelii” - przewrotu, który zdołał zachwiać tradycyjnym wzrokowym dominium. Wydaje sięjednak, iż współczesna kultura, niepomna na podejmowane od schyłku XIX w. rozmaite próby obalenia niepodzielnej władzy wzroku, po raz kolejny popada w pułapkę „fetyszyzmu spojrzenia”.3. Badacze diagnozują nastanie społeczeństwa ekranów, „,kultury piktorialnej” oraz, tym samym, nowej figury kulturowej podmiotowości - homo videns ${ }^{4}$. Niniejszy artykuł ma na celu opozycyjne usytuowanie synestezji wobec wzrokocentrycznej machiny kulturowej oraz wskazanie na sprzeciwiające się okulocentrycznej wizji świata kulturowe doświadczenia synestetyczne wieku XXI.

Rozwijany w XX w. dyskurs antywzrokocentryczny przebiegał wedle M. Jaya wokół trzech osi przeobrażeńs. Po pierwsze, w ramach antywizualnej rewolucji nastąpiła stopniowa detranscendentalizacja perspektywy. Wraz z ogłoszeniem „śmierci boga” (emblematyczne Gott ist tot) przez Fryderyka Nietzschego, zawieszeniu uległ kartezjański wymiar boskiego spojrzenia. Uniwersalna optyka transcendentalna zastąpiona została „wielością perspektyw partykularnych"6. Na gruncie literatury wiązało się to z odrzuceniem narracji auktorialnej na rzecz personalnej; w malarstwie oznaczało zaś

1 J.Przeźmiński, Z perspektywy Martina Jaya, czyli o tym jak , przymknać” oko, [w:] R. Nycz(red.), Odkrywanie modernizmu, Kraków 2004, s. 331-332.

2 Zob. M. Jay, Kryzys tradycyjnej władzy wzroku. Od impresjonistów do Bergsona, [w:] R. Nycz (red.), Odkrywanie modernizmu, Kraków 2004.

3 Tamże, s. 305

4 Zob. G. Sartori, Homo videns. Telewizja i post-myślenie, Warszawa 2007; R. Cieślak, Uwolniony w obrazie-uwięziony w spojrzeniu, [w:] J. Potkański, R. Pruszczyński (red.), Spojrzenie - spektakl - wstyd, Warszawa 2011.

5 Zob. M. Jay, dz. cyt., s. 318.

6 J. Przeźmiński, dz. cyt., s. 342. 
zaniechanie stosowania obowiązkowej od renesansu siatki perspektywicznej. Po drugie, antywzrokocentryzm dokonał rewaloryzacji czasu w stosunku do przestrzeni, czego najznamienitszym exemplum literackim jest siedmiotomowe dzieto W poszukiwaniu straconego czasu Marcela Prousta - kuriozalna próba odtworzenia w sztuce ludzkiego doświadczenia czasowości.

Trzecim obszarem radykalnych przemian, zainicjowanych przez przedstawicieli dyskursu antywzrokocentrycznego, była rekorporalizacja podmiotu myślącego - swoisty „powrót ciała”, wygnanego z ukształtowanej pod przemożnym wpływem filozofii kartezjańskiej zachodniej formuły podmiotowości. Antyokulocentryzm ponownie włączył kategorię cielesności do koncepcji podmiotu. Ogromną rolę odegrał w tym procesie H. Bergson, który - dokonawszy mariażu materializmu z idealizmem - wypracował nowy model holistycznej podmiotowości'. Na gruncie sztuk plastycznych, ale

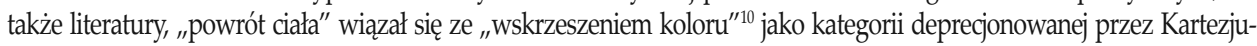
sza $^{11}$ - głównego fundatora dyktatury spojrzenia. Malarze sięgać zaczęli po nowe odcienie, literaci-symboliści dostrzegli w kolorze potencjał sensotwórczy ${ }^{12}$.

Obdarzony ciałem podmiot zaniechał oglądu świata z bezpiecznej kartezjańskiej perspektywy na rzecz uwikłania w rzeczywistość czy też rzeczywistości. Cielesność artysty zaczęła ujawniać się w jego dziele. Somatyczne doświadczenie

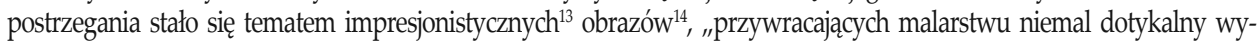
miar" $^{\prime \prime 2}$. Modernistyczny „powrót ciała”, znamionowany przez włączenie kategorii cielesności w proces twórczy oraz artystyczne sproblematyzowanie cielesnego doświadczenia postrzegania, był projektem holistycznej, antykartezjańskiej podmiotowości. Obecnie, w kontekście niedawno rozpoznanego „zwrotu somatycznego", cielesność staje się istotnym tematem, a zarazem narzędziem badań kulturowych, literackich oraz socjologicznych.

Środkiem, który znakomicie sprawdza się w artystycznym wyrażaniu cielesności, jest synestezja - twórczy „dialog zmysłów” ${ }^{\prime \prime}$ w ramach którego „pewne doznania zmysłowe są przedstawiane w kategoriach właściwych innym zmysło$\mathrm{m}^{\prime \prime 16}$. Anna Łebkowska, autorka terminu „,Somatopoetyka”, stwierdza, iż współcześnie to właśnie synestezja „zyskuje rangę miejsca, $\mathrm{w}$ którym przecina się dyskurs poetyki i cielesnośs' ${ }^{\prime \prime 17}$. Synestezja akcentuje cielesność postrzegającego podmiotu, podważając kartezjańskie, wzrokocentryczne rozgraniczenie na res cogitans, podmiot myślaç i res extensa, materialny przedmiot, objawiający się obserwującej go świadomości w pełnej jasności obiektywnego poznania. Jest to jedna z trzech głównych przyczyn, dla których uważam synestezję za modelowy instrument dyskursu antywzrokocentrycznego.

Współcześnie metafora intersensualna staje się narzędziem antyokulocentryzmu, przede wszystkim jako nośnik jego głównych składników ideowych, tj. postulatu zarzucenia kartezjańskiego perspektywizmu („,detranscendentalizacji perspektywy ${ }^{\prime \prime 18}$ ) oraz ucieleśnienia („,rekorporalizacji1 ${ }^{\prime 19}$ ) podmiotu myślącego, tradycyjnie oddzielanego od materii - wedle kartezjańskiej, okulocentrycznej maksymy Cogito ergo sum - nieprzekraczalną granicą świadomości. Synestezja somatyzuje podmiot, znosząc rozróżnienie , „ja" - „ciało", , ,jaźn" - „, materia”.

Drugą przesłanką wskazującą na antywizualność synestezji jest banalny fakt, iż burzy ona zachodnią hierarchię zmysłów, zbliżając, kojarząci plącząc kanały sensualne, utrzymywane przez okulocentryczną kulturę w posłusznym, klarownym porządku. Stephen Ullmann przeprowadził rozległe statystyczne badania nad metaforycznymi transferami synestetycznymi w literaturze romantycznej. Badacz rozważał przede wszystkim kierunek transferów intersensorycznych, posługując się przy tym emblematyczną (zachodnią) hierarchią zmysłów. Zaproponowana przez S. Ullmanna klasyfikacja

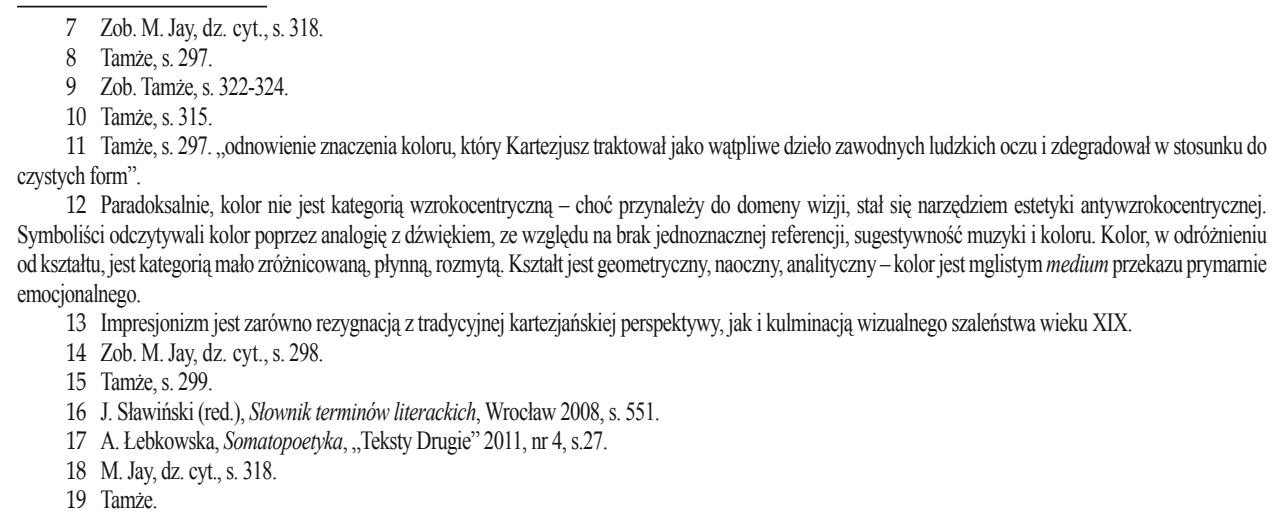


zmystów określa wzrok jako domenę nadrzędną. W istocie, wizja generuje największąilośćjęzykowych określeń, metafor, epitetów; jest kategorią analityczna, detaliczna, statyczną - unieruchamiającą zmysłowe panta rhei w naocznym, segmentacyjnym ładzie. Następnym w kolejności zmysłem wyróżnionym w sensualnej piramidzie S. Ullmanna jest bogata leksykalnie domena słuchu; poniżej zaś tych dwóch „,silnie" reprezentowanych w języku modalności zmysłowych znajdują się kolejno coraz mniej zróżnicowane kategorie: węchu, smaku oraz dotyku. Synestezja, oddając głos innym zmysłom, obala tradycyjną hegemonię spojrzenia nad słuchem, powonieniem, haptyką oraz smakiem.

Trzecim symptomem antyokulocentryzmu synestezji jest jej niezwykła zdolność do unifikacji doświadczenia. S. Ullmann, przebadawszy imponującą ilość literackich romantycznych metafor intersensualnych, uznał, iż w zdecydowanej większości przebiegają one wzwyż hierarchicznej struktury sensorium: oznacza to, iż zazwyczaj kategorie niższe, mniej zróżnicowane użyczają swoich środków opisu do wyrażenia treści przynależnych do wyższych, bardziej precyzyjnych kategorii zmysłowych; słowem, łatwiej o synestezję typu: „miękki głos" niż „,cicha won'. Przytłaczająca dominacja transferów oddolnych nad odgórnymi skłoniła S. Ullmanna do sformułowania uogólnionego wniosku na temat kierunku metafor intersensorycznych - tendencję rosnącą odważył się nazwać panchronistyczna, a zatem ponadczasową, niepodległa zarówno synchronicznym trendom współczesnym, jak i diachronicznej zmienności historycznej.

W 2007 r. Reuven Tsur dokonał funkcjonalnej reinterpretacji powyższego modelu, sugerując, iż oddolne transfery intersensoryczne, a więc znakomita większość wszelkich metafor synestetycznych, służy uzyskaniu jakości ekstatycznej w odbiorze tekstu literackiego. Rzadsze, odgórne transfery, mają według badacza na celu osiągnięcie efektu intelektualnego, konceptualnego - takie synestezje występuja, gwoli przykładu, w poezji barokowej, obliczonej na dowcip, zdziwienie, olśnienie czytelnika przemyślanym chwytem ${ }^{20}$.

Efektem typowej (panchronistycznej) synestezji ekstatycznej jest zatem wyzwalające wrażenie scalającej pełni, czasami wręcz $m$ is s y c $z \mathrm{n}^{21}$ doznanie zintegrowania doświadczenia ${ }^{22}$. Gdy panowanie wzroku zostaje poddane $\mathrm{w}$ watpliwość poprzez przywołanie środków wyrazu kategorii niższych, mniej od wizji zróżnicowanych, nastąpić musi ujednolicenie doświadczenia - świat o glą d a n y przez pryzmat d o t y ku jest światem mniej analitycznym i skatalogowanym, a bardziej intuicyjnym od uniwersum spojrzenia ${ }^{23}$. Ihab H. Hassan, badając "manifest” synestezyjnej ekstazy poetyckiej- słynne Correspondances Charlesa Baudelaire'a, stwierdza: „synestetyczny obraz odzwierciedla pewną całość, niezahamowaną przez logiczne klasyfikacje. Umożliwia czytelnikowi kontakt z potężną zmysłową obecnościa, prymitywną jednością czy też syntezą wrażen'" ${ }^{\prime 2}$.

Ta niezwykła właściwość estetyki synestetycznej posiada także motywację natury biologicznej. Artystyczny chwyt synestezji jest sui generis transpozycją synestezji klinicznej - uwarunkowanego genetycznie zaburzenia percepcji, polegającego na trwałym sprzężeniu dwóch ośrodków zmysłowych ${ }^{25}$. Określona stymulacja sensoryczna aktywuje u synestety percepcję zwielokrotnioną: zarówno odpowiadającą bodźcowi wejściowemu, jak i suplementarna, w obrębie powiązanej modalności. Intersensoryczny, synestezyjny ogląd świata jest uniwersalnym zjawiskiem wczesnorozwojowym - kliniczna synestezja jest normalnym trybem percepcji dziecięcej, zanikającym w wyniku procesu apoptozy, „programowej śmierci komórek" ${ }^{\prime 26}$, prowadzącej do ucinania „zbędnych" połączeń neuronalnych w mózgu dziecka. Anomalie w przebiegu apoptozy skutkować mogą trwałą synestezją kliniczną. Ustępowanie naturalnie synestetycznego, holistycznego stylu

20 Odgórne transfery synestetyczne występujące w poezji barokowej, np. a loud perfume (głośny zapach) w Elegii IV angielskiego poety metafizycznego Johna Donne’a, dokonują - wedle funkcjonalnego modelu R. Tsura - analitycznej „dyferencjacji” doświadczenia. Znacznie częstsza panchronistyczna synestezja ekstatyczna kreuje natomiast efekt „dedyferencjacji” (a więc unifikacji) doznań (Por. R. Tsur, Issues in Literary Synaesthesia, "Style” 2007, vol. 41, no. I). Barokowe transfery intersensualne opisujące doznania dotykowe, węchowe i gustatoryczne za pomocą językowych wykładników domeny wzorku bądź shuchu swoiście prześwietlają oraz manieryzują ich językową nieokreśloność (reprezentacja zmysłów w języku jest bowiem niejednolita i nieproporcjonalna - gwoli przykładu, wizja dominuje nad węchem pod względem bogactwa związanej z nią leksyki w językach europejskich);Dot. koncepcji poezji jako „mowy utudnionej”, wytrącającej czytelnika z automatyzmu percepcji za pomoca ,chwytu”, Zob. W. B. Szkłowski, Sztuka jako chwyt, [w:] S. Skwarczyńska (red.), Teoria badań literackich za granicą: antologia, T. 2, cz. 3, Kraków 1986.

21 Zob. R. Tsur, Issues in Literary Synaesthesia, dz. cyt., s. 44.

22 Wedle R. Tsura efektem transferu oddolnego jest „dedyferencjacja”, przejście od domeny wysoce ustrukturyzowanej do domeny ,jakości bezpostaciowych".

23 Według R. Tsura dążenie do unifikacji doświadczenia jest głównym motorem poezji: „Jednym z moich głównych założeń w poetyce kognitywnej jest twierdzenie, że poezja w ogóle, a ściślej język figuratywny polega na nieustannym poszukiwaniu sposobów na przezwycięzenie tyranii wysoko zróżnicowanych kategorii językowych" (Tamże, s. 34.)

24 I. H. Hassan, Baudelaire's Correspondances : The dialectic of a poetic affinity, 'The French Review" 1954, Vol. 27, No. 6, s. 439.

25 Zob. S. Baron-Cohen, J. E. Harrison (red.), Synaesthesia: classic and contemporary readings, Oxford 1997, s. 3.

26 R. Carter, Tajemniczy świat umystu, Poznań 1999, s. 21-22.

OGRODY NAUK I SZTUK NR 2014 (4) 
doświadczania, bywa kojarzone przez niektórych naukowców z akwizycją języka²7.Jest ton, pojmowany jako narzędzie dyferencjacji, klasyfikacji i etykietyzacji pojedynczych elementów doświadczenia, sprzyja analitycznej, fragmentaryzującej doświadczenie wizji. Język to surowy system, dzielący świat na niezliczone klasy, jakości, typy. Przyswajanie języka naturalnego wiąże się zatem ze stopniowym wykształcaniem umiejętności kategoryzacji świata ${ }^{28}$, identyfikacji rozmaitych przedmiotów percepcji. Nie sprzyja temu synestezja, myląca zapachy z kolorami, dźwięki ze smakiem. Język unicestwia holistyczne, „pierwotne" przeżywanie dostępne dzieciom - naturalnym synestetom. Kuszące zdaje się uwypuklenie, w zarysowanym powyżej kontekście językowym, rozwojowego aspektu lateralizacji półkul mózgowych: półkula prawa steruje myśleniem holistycznym, poza- i przedjęzykowym, metaforą oraz dowcipem; dominacja półkuli lewej, odpowiedzialnej za analityczny język, wiąże się z supresją prawopółkulowej, kompleksowej wizji świata, w którą harmonijnie wpisuje się ekstatyczna, scalająca metafora synestetyczna ${ }^{29}$.

Synestezja podważa zatem sterylna, językową segmentację świata poprzez regresję do bardziej prymitywnego trybu holistycznej, dziecięcej percepcji. Intersensoryczna metafora przywraca zatracony w dzieciństwie, płynny, całościowy ogląd świata nieposegregowanego jeszcze na smaki i obrazy, dźwięki, wonie i dotyk. Synestezja rewaloryzuje ciało jako źródło nie tylko poli-, ale wręcz intersensorycznego doświadczenia, przezwyciężając tym samym uświęcony filozoficzną oraz estetyczną tradycją prymat wzroku. Synestezja unieważnia hierarchiczną strukturę kulturowego sensorium oraz godzi w promowaną przez kartezjański okulocentryzm „mechanistyczną koncepcję aparatu poznawczego" ${ }^{\text {"30 }}$ - myślącego (nie zaś: dotykającego, czującego, słyszącego, smakującego) „ja”", wiernie odbijającego w przejrzystym lustrze świadomości niezmącony, obiektywny obraz materialnego świata. Synestezja to wehikuł antyokulocentrycznego przesłania, wybrzmiewającego nawet $\mathrm{w}$ wizualnej kulturze XXI w.

Jednym z atrakcyjnych kulturowych doświadczeń intersensorycznych dwudziestego pierwszego stulecia jest synestetyczne kino Davida Lyncha. Zmysłowej rozbiórce poddać warto powstały w 2001 r. Mulholland Drive - obraz aranżujący „intersensoryczne doświadczenie, pokrewne synestezji w ujęciu B. Massumi'ego, użytecznie łączącego definicje naukowe, opisy empiryczne z podejściem wyobraźniowym, abstrakcyjnym ${ }^{\prime \prime 31}$. Na czym polega kinematograficzna synestezja w Mulholland Drive? Co stanowi o intersensoryczności filmu? W jaki sposób kino, uznawane tradycyjnie za prawdziwy tryumf spojrzenia (określenie „,kinematograficzny” znaczyło dla H. Bergsona tyleż co „,wzrokocentryczny" ${ }^{\prime \prime 2}$ ) przełamać może rygor okulocentryzmu?

Film jest zasadniczo medium dwukanałowym, integrującym wizję z fonią. Współcześnie kino przekracza zmysłowe granice tkanki filmowej, inkorporując do doświadczenia kinematograficznego rozmaite bodźce sensualne spoza domeny wzroku oraz słuchu. Wykorzystując techniki obrazowania 3D, kino kreuje iluzję głębi kinetycznej, zastępując ",oglądanie" filmu na płaszczyźnie ekranu przestrzennym „byciem” w nim. Kino 5D, angażujące dodatkowo węch, dotyk oraz kinezę, tworzy polisensoryczne wydarzenie filmowe, zastępując bierną figurę „widza” nowym modelem „uczestnika”. Kino staje się w ten sposób symulakryczną rzeczywistościa, której się nie „obserwuje”, lecz w którą się „"wkracza”. Kino 3D i 5D to antywzrokocentryczne projekty polisensoryczne, nie dające się jednak sklasyfikować jako synestetyczne. Polisensoryczność jest jednoczesnym uruchomieniem wielu kanałów zmysłowych, synestezja - jest ich dialogiem. W kontekście synestezji należałoby rozpatrywać metody, za pomocą których wizualno-audytywne doświadczenie kinematograficzne stara się wyrazić, za pośrednictwem dwóch kanałów sensualnych, inne wrażenia zmysłowe: smaku, dotyku, zapachu ${ }^{33}$.Zabiegi te należałoby rozumieć jako swoisty przekład intersensoryczny zjednego zmysłu na inny. W jaki sposób Mulholland Drive dokonuje translacji doznań haptycznych, woni, termiki na wizję oraz dźwięk?

Jennifer M. Barker dokonała analizy filmu Mulholland Drive pod kątem jego synestetyczności, rozumianej za Brianem Massumim jako „widzialne, wyczuwalne »złącze« pomiędzy dwoma systemami zmysłowego postrzegania: wizu-

27 Zob. J. M. Barker, Out of Sync, Out of Sight: Synaesthesia and Film Spectacle, ”Paragraph” 2008, nr 31:2, s. 243. „Massumi zgadza się z badaniami sugerującymi, iż synestezja jest normalnym trybem dziecięcej percepcji, zanikającym wraz z akwizycją języka".

28 Na temat zagadnienia kategoryzacji językowej zob. J. R. Taylor, Kategoryzacja w języku. Prototypy w teorii językoznawczej, Kraków 2001. Zob. G. Lupyana, D. Mirmanb, Linking language and categorization: Evidence from aphasia, http://sapir.psych.wisc.edu/papers/lupyan_mirman_inPress.pdf, 15.12.2013.

29 Dot. dominacji półkulowej zob. S. P. Springer, G. Deutsch, Lewy mózg, prawy mózg. Z perspektywy neurobiologii poznawczej, Warszawa 2004.

30 Zob. M. Jay, dz. cyt.

31 J. M. Barker, dz. cyt., s. 244.

32 Zob. M. Jay, dz. cyt., s. 326: „Bergson, dokonując wyboru terminu »kinematograficzny«, aby potępić wzrokocentryczne tendencje zachodniej metafizyki, zachodniej nauki, a nawet zwykłego języka, wyrażał nieufność wobec prymatu wzroku, obejmującego swym zasiegiem również nową technologię".

33 Analizę filmu synestetycznego można przeprowadzać na dwóch poziomach: formy oraz fabuły. W niniejszym artykule wskazane zostaną formalne środki transferu intersensorycznego - rozpatrzone zostanie synestetyczne doświadczenie kina z perspektywy odbiorcy. Możliwa jest niemniej także analiza intersensorycznej budowy świata przedstawionego z perspektywy bohatera(ów) filmu. 
alno-kognitywnym oraz propriocepcyjnym ${ }^{\prime \prime 34}$. Synestezja jest trybem odbioru sprzeciwiającym się ewidentnej, linearnej „mapie" ${ }^{\prime 35}$ wizualnej, jest doświadczeniem desynchronizacji propriocepcyjnego oraz naocznego „systemu referencji” ${ }^{\prime \prime 36}$. Według J. M. Baker, w Mulholland Drive „niebieska skrzynka i korytarz oraz sceny kręcone w i obok nich, działają raczej

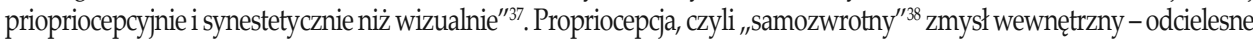
poczucie położenia oraz pozycji własnego ciała w przestrzeni, staje się w filmie D. Lyncha samodzielnym trybem fokalizacji, przeplatającym się z wizualna, „zewnętrzną" perspektywą. Kamera przyjmuje momentami propriocepcyjny punkt widzenia bohaterów: jej ruch traci stabilność, jej wizja - ostrość. Kamera staje się spojrzeniem bohaterów, więcej: staje się ich cielesną percepcja, ich oddechem, gorączka, chwiejnym ruchem ich ciał. Również fonia niejako przenosi się do wnętrza ciała protagonisty: słyszymy szum jego krwi, bicie jego serca. Film staje się propriocepcyjnym filtrem, poprzez który widz doznaje naznaczonego cielesnością bohatera świata przedstawionego. Chwyt ten funkcjonuje analogicznie do literackiej narracji personalnej, będącej de facto jedną ze spektakularnych zdobyczy dyskursu antywzrokocentrycznego.

Synestetyczność Mulholland Drive polega nie tylko na zastępowaniu wizualnego systemu referencji propriocepcyjnym. W filmie dostrzec należy także przekład wrażeń z jednej domeny zmysłowej na drugą - jest tak w przypadku dotyku, tłumaczonego na kod optyczny. Obraz sprawia miejscami wrażenie dotykalnego, zwłaszcza podczas wyjątkowo długich zbliżeń, gdy kamera "napiera na twarz"39 bohatera - np. podczas wykonania wokalnego utworu muzycznego Llorando („Płacząc”) przez artystkę Rebekę Del Rio: „wyczuwalna bliskość i intensywność tego obrazu czyni [jej - przyp. autora] występ doświadczeniem równie dotykalnym, co wizualnym i audytywnym" ${ }^{\prime \prime 0}$.

Mulholland Drive jest filmem antyokulocentrycznym, podważającym omnipotencję wzroku poprzez wyparcie percepcyjnej „mapy wizualnej” na rzecz postrzegania propriocepcyjnego oraz synestetycznego. Unieważniając supremację wzroku, wskazuje na pozawizualne doświadczenie rzeczywistości, wymykające się restrykcyjnej racjonalności: „niebieska skrzynka całkiem dosłownie znika z pola widzenia, przerywając ciąłość wizji, by dać nam przedsmak rzeczywistości

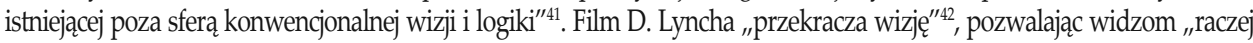
poczuć niż zobaczyć owe dwa systemy referencji - wizualny oraz pozawizualny - napierające na siebie nawzajem, ulegające de- i synchronizacji zgodnie z opisami B. Massumiego ${ }^{\prime \prime 43}$.

Innego rodzaju współczesnym przejawem antywzrokocentryzmu jest synestetyczne doświadczenie przestrzeni i obiektu. Według Diny Ricco, wraz z rozkwitem nowoczesnych technologii krystalizuje się „nowa figura projektanta jako synestetycznego animatora, (...) aranżera wrażeń, zdolnego do pracy z tekstami, liczbami, a także dźwiękami, bodźcami haptycznymi etc. w celu uzyskania wzajemnej ich kongruencji" ${ }^{\prime \prime 4}$. Design oraz architektura XXI w., eksploatując świeże zdobycze technologiczne, przekształcają tradycyjnie statyczne oraz monosensualne doświadczenie przedmiotu oraz przestrzeni. Przykładem zastosowania mechanizmu synestezji w architekturze jest zaprojektowany przez Stefana Rutzingera oraz Kristinę Schinegger Synaesthetic Filter, elastyczna hala koncertowo-sceniczna, która „podobnie jak wyłaniajacy się z niej dźwięk, (...) nie jest stałą forma, lecz migotliwą obecnością. Nie tworzy zamkniętej przestrzeni, do której można wkroczyć, lecz synestetyczne doświadczenie, w które się zanurzasz" ${ }^{45}$. Przenośny pawilon można modelować dowolnie w zależności od projektu wydarzenia. Co więcej, amorficzny Synaesthetic Filter może zmieniać kształt również w trakcie spektaklu, pozyskując nowe właściwości akustyczne: „Dzięki rotacyjnym elementom akustycznym, pawilon może być zamykany i otwierany w celu synchronizacji zmiennych wizualnych, przestrzennych i akustycznych jakości sali podczas występó $w^{\prime \prime 46}$. Działanie stworzonego przez S. Rutzingera oraz K. Schinegger pawilonu przyrównać można do pracy

34 J. M. Barker, dz. cyt., s. 241.

35 Zob. Tamże, s. 245.

36 Zob. Tamże.

37 Tamże, s. 248

38 Tamże, s. 243.

39 Tamże, s. 240

40 Tamże.

41 Tamże, s. 248

42 Tamże, s. 250.

43 Tamże.

44 D. Riccò, A. Belluscio, S. Guerini, Design for the Synaesthesia. Experimentation on Audio, Visual and Haptic correspondences in the Basic Design course, Lisbon 2003, s. 159.

45 R. Sykes, Synaesthetic Filter by Stefan Rutzinger \& Kristina Schinegger, http:/www.dezeen.com/2009/01/18/synaesthetic-filter-by-stefan-rutzingerkristina-schinegger/, 13.12.2013.

46 Tamże.

OGRODY NAUK I SZTUK NR 2014 (4) 
thumacza symultanicznego, dokonującego w czasie rzeczywistym przekładu z kodu wyjściowego na docelowy - w tym przypadku byłaby to translacja dźwięku na obraz oraz kinezę.

Możemy sobie wyobrazić, jak spektakularnym byłoby odtworzenie w Synaesthetic Filter słynnego synestetycznego koncertu Aleksandra Scriabina z 1915 r., podczas którego wykonaniu Prométhée ou le Poème du feu towarzyszył unikalny pokaz świetlny. A. Scriabin stworzył synestetyczny clavier à lumières, „,klawiaturę świetlną", idiosynkratyczny system odpowiedników pomiędzy dźwiękami a k o lo r a m i. W jego konstrukcji wykorzystał własne empiryczne doświadczenie synestezji klinicznej ${ }^{47}$. Przeróżne instrumenty emitujące dźwięki oraz kolory, pokrewne clavier à lumières Scriabina, tworzone były od wieku XVIII ${ }^{48}$

Interesującą inicjatywą kulturową realizowaną od zaledwie dwóch lat jest koncept Syndyn Artistic Sports Game ${ }^{49}$, nowatorski projekt artystyczno-sportowy opracowany przez zespół Ekta. SASG synestetycznie łączy cielesną taktylno-kinetyczną aktywność sportową z dynamicznym audio-wizualnym spektaklem. Spersonalizowany krajobraz dźwiękowy (soundscape) i odpowiadające mu kolory, wybierane są przez gracza na ekranie dotykowym iPoda. Tłumacząc dotyk (np. lotki na rakiecie ze wbudowanymi czujnikami) oraz ruch (np. wyposażonej w luminescencyjną diodę lotki w powietrzu) na efekty świetlne oraz dźwiękowe, SASG przekształca dowolne wydarzenie sportowe w odbywający się w czasie rzeczywistym synestetyczny performance. Zaprojektowane przez Ekta wydarzenie sportowe staje się jednocześnie dziełem sztuki, uwiecznionym pod postacią fotografii z długim czasem ekspozycji - obrazu malowanego kolorowym świałtem wzdłuż trajektorii lotki oraz wokół ruchu rozświetlonych ramion i rakiet. SASG to fascynująca „fuzja fizycznego ruchu, estetyki, rozrywki oraz technologii" ${ }^{\prime 50}$, stanowiąca znakomite rozpoznanie roli, jaką odgrywać może mechanizm synestezji we współczesnych przedsięwzięciach antyokulocentrycznych, czerpiących z zaawansowanych technologii XXI w.

Czy możliwe jest synestetyczne doświadczenie trwania? Czas jest sam w sobie, według antywzrokocentrycznego filozofa H. Bergsona, lekarstwem na dyktaturę spojrzenia ${ }^{51}$. Wartość czasu jest zazwyczaj odczytywana poprzez kanał wzrokowy bądź słuchowy - zegar tradycyjny jest narzędziem łączącym kinetykę wskazówek z graficznym wizerunkiem tarczy oraz dźwiękiem (tykania wskazówek, wybijania godziny), współczesny zegar elektroniczny zaś ogranicza się przeważnie do bodźca wzrokowego, rezerwując kanał słuchowy dla wyłącznej funkcji budzika. Wonne zegary typu Wake n'Bacon czy Osim Nioi to efektowne rezultaty transferu audytywnej informacji budzika na kod olfaktoryczny. Wake n’Bacon jest urządzeniem, które budzi za pomocą woni (np. smażonego bekonu). Tego typu urządzenia wykorzystują woń nie tylko do pobudki, ale także do aromaterapii (np. pomagający zasnąć zapach lawendy) oraz do wskazywania czasu podczas całego dnia. Kartridże z zapachami wonnych zegarów można dowolnie zaprogramować.

Zegary zapachowe wykorzystują wyniki badań nad wpływem poszczególnych woni na funkcjonowanie kognitywne człowieka $^{52}$ - zapach drzewa sandałowego działa jak naturalny środek uspokajający, wonie cytrusów pobudzają uwagę, zapach jabłka łagodzi ból głowy, zaś woń bazylii stymuluje pracę kory przedczołowej mózgu, poprawiając funkcjonowanie pamięci krótkotrwałej. Zegar zapachowy firmy Hammacher Schlemmer włącza do doświadczenia czasu także odgłosy natury oraz delikatne światło. Synestetyczny zegar nie jest wynalazkiem XXI w. - urządzenia chronometryczne wykorzystujące kadzidła znane były już w Chinach Dynastii Song. Współczesne wonne zegary wskrzeszają zapomnianą tradycję pozawizualnego doświadczenia trwania.

Nie mniej intrygujące wydają się możliwości wykorzystania synestetycznego transferu w edukacji. Dyskurs naukowy, jako królewska domena wzrokocentryzmu, zjednej strony faworyzuje, z drugiej zaś dyskwalifikuje określone metody dydaktyczne. Laura Seargeant Richardson wysuwa hipotezę na temat pedagogicznego potencjału intersensualnych materiałów edukacyjnych. Według autorki wprowadzona niedawno na rynek zabawek synestetyczna „,kreda i okulary 3D, dzięki którym kolory zdają się odrywać się od ziemi" ${ }^{25}$ może „zrewolucjonizować nauczanie ${ }^{\prime 54}$. Badaczka eksploruje kontrowersyjny koncept „wonnego alfabetu”: „Dlaczego litery alfabetu nie mają zapachowych odpowiedników? (...) Jako

47 Nie jest to pewne. Argumentacja na rzecz obalenia tezy o klinicznej synestezji A.Scriabina vide: B. M. Galeyev, I. L. Vanechkina, Was Scriabin a Synesthete?, ,Leonardo" 2001, vol. 34, no. 4, s. 357-361.

48 Zob. K. Peacock, Instruments to Perform Color-Music: Two Centuries of Technological Experimentation, "Leonardo" 1988, vol. 21 no. 4, s. $397-406$.

49 http://3kta.net/syndyn/, 10.12.2013

50 Tamże.

51 Zob. M. Jay, dz. cyt.

52 Zob. The fragrance clock. Improve your life with fragrance, http://www.menshealth.co.uk/style/skin-care/the-fragrance-clock-314218, 13.12.2013.

53 L. S. Richardson, Seeing the Future Synesthetic, http://designmind.frogdesign.com/articles/the-substance-of-things-not-seen/seeing-the-future-synesthetic.html, 13.12.2013.

54 Tamże. 
gatunek nigdy nie zapominamy woni. Co dałby nam wonny alfabet, nawet jeśli każdy z nas stworzyłby jego unikatowa, osobistą wersję? Zyskalibyśmy głębsze i polepszone zrozumienie tego spreparowanego przez człowieka konstruktu. Pomógłby w zapamiętywaniu, nauce, skojarzeniach i rozumieniu. Dla osób niewidomych, litera »A«, której nie mogą zobaczyć, podlegałaby teraz interpretacji oraz rozpoznaniu w oparciu o inną zmysłową cechę. Byłaby to możliwość głębszego poznania oraz przyswojenia litery »A«. Byłby to bodziec, aktywujący adaptacyjny potencjał mózgu" ${ }^{\prime \prime 5}$.

L. S. Richardson sonduje także ideę przestrzennej matematyki, czerpiącej z technologii obrazowania 3D: „Poprosiłam ich, by wyobrazili sobie postrzeganie matematyki w całkowicie nowy sposób - liczby pierwsze przynależałyby do osobnej, unikalnej płaszczyzny wizualnej, a liczby nieparzyste byłby odróżnialne od parzystych. Zamiast polegać na pamięciowym przyswajaniu faktów, uczniowie mogliby założyć okulary 3D i naprawdę zobaczyć różne liczby w różnych fizycznych przestrzeniach"56. Do zacytowanej powyżej „ekstazy naoczności” dodałabym: naprawdę poczuć, dotknąć, usłyszeć, być wśród „różnych liczb w różnych fizycznych przestrzeniach". Przedwczesny - zwłaszcza w kwestii wonnego alfabetu - entuzjazm L. S. Richardson nie jest niemniej bezzasadny. Zwłaszcza w świecie wysokich technologii synestezja wykazuje znaczny potencjał na polu edukacji i nie jest mylnym stwierdzenie autorki, iż „ignorując potencjał naszych zmysłów, tracimy możliwość efektywniejszego uczenia się ${ }^{\prime \prime 57}$.

Współcześnie synestetyczność staje się taktyką antywzrokocentrycznych reorientacji w obrębie kultury wizualnej. Wzrokocentryzm kultury XXI w. bywa podważany poprzez alternatywne kinematograficzne, architektoniczne, sportowo-artystyczne, a nawet chronometryczne doświadczenia synestetyczne, znoszące milczenie oraz inicjujące dialog pozawizualnych źródeł poznania. Synestezja jest doskonałym argumentem antywzrokocentryzmu i jako taka dochodzi do głosu nawet $\mathrm{w}$ kulturze określanej jako prymarnie piktorialna. Niezbadanym pozostaje pełny potencjał mechanizmu synestezji dla takich domen kultury, jak edukacja czy sport - potencjał, który „obrazkowa” kultura XXI w. zaczyna dopiero dostrzegać.

\section{Bibliografia}

[1] Barker J. M., Out of Sync, Out of Sight: Synaesthesia and Film Spectacle, "Paragraph" 2008, nr 31:2.

[2] Carter R., Tajemniczy świat umystu, Poznań 1999.

[3] Cieślak R., Uwoolniony w obrazie - uwwiezziony w spojrzeniu, [w:] Potkański J., Pruszczyński R. (red.), Spojizzenie - spektakl - wstyd, Warszanwa 2011.

[4] Galeyev B. M., Vanechkina I. L., Was Scriabin a Synesthete?, "Leonardo" 2001, Vol. 34, No. 4.

[5] Hassan I. H., Baudelaire's Correspondances: The dialectic of a poetic affinity, "The French Review" 1954, Vol. 27, No. 6.

[6] Jay M., Kryzys tradycyjnej władzy wzroku. Od impresjonistów do Bergsona, [w:] Nycz R. (red.), Odkrywannie modernizmu, Kraków 2004.

[7] Łebkowska A., Somatopoetyka, „Teksty Drugie" 2011, nr 4.

[8] Peacock K., Instruments to Perform Color-Music: Two Centuries of Technological Experimentation, "Leonardo" 1988, Vol. 21 , No. 4.

[9] Przeźmiński J., Z perspektywy Martina Jaya, czyli o tym jak ",przymknące oko, [w:] Nycz R. (red.), Odkrywanie modernizmu, Kraków 2004.

[10] Riccò D., Belluscio A., Guerini S., Design for the Synaesthesia. Experimentation on Audio, Visual and Haptic correspondences in the Basic Design course, Lisbon 2003.

[11] Sartori G., Homo videns. Telewizja i post-myślenie, Warszawa 2007.

[12] Slawiński J. (red.), Stownik terminów literackich, Wroclaw 2008

[13] Springer S. P., Deutsch G., Lewoy mózg, prawy mózz. Z perspektywuy neurobiologii poznawczej, Warszawa 2004.

[14] Szkłowski W. B., Sztuka jako chwyyt, [w:] S. Skwarczyńska (red.), Teoria badań literackich za granica: antologia, T. 2, cz. 3, Kraków 1986.

[15] Taylor R., Kategoryzacja w jezzyku. Prototypy w teorii jezykoznawuczej, Kraków 2001.

[16] Tsur R., Issues in Literary Synaesthesia, "Style" 2007, Vol. 41, No. I.

[17] Ullmann S., Panchronistic Tendecies in Synaesthesia, [w:] Ullmann S., The Principles of Semantics, Blackwell 1957.

\section{Netografia}

[18] Donne J., Elegia IV, [w:] John Donne. Poems, http://www.poemhunter.com/i/ebooks/pdf/john_donne_2004_9.pdf, 13.12.2013.

[19] Lupyana G., Mirmanb D., Linking language and categorization: Evidence from aphasia, http://sapir.psych.wisc.edu/papers/lupyan_mirman_inPress.pdf, 13.12.2013.

[20] Richardson L. S., Seeing the Future Synesthetic, http://designmind.frogdesign.com/articles/the-substance-of-things-not-seen/seeing-the-futuresynesthetic.html, 13.12.2013.

[21] Sykes R., Synaesthetic Filter by Stefan Rutzinger \& Kristina Schinegger, http://www.dezeen.com/2009/01/18/synaesthetic-filter-by-stefan-rutzinger-kristina schinegger/, 13.12.2013.

[22] The fragrance clock. Improve your life with fragrance, http://www.menshealth.co.uk/style/skin-care/the-fragrance-clock-314218, 13.12.2013.

FILMOGRAFIA

[23] Lynch D. (reż.), Mulholland Drive, 2001.

\section{Tamże. \\ 56 Tamże.}

57 Tamże. 